\title{
Streamlining and Refining FEDS Loads Models - Final Report
}

\author{
RT Dahowski \\ JA Dirks
}

February 2013

Pacific Northwest

NATIONAL LABORATORY

Proudly Operated by Battelle Since 1965 


\title{
DISCLAIMER
}

This report was prepared as an account of work sponsored by an agency of the United States Government. Neither the United States Government nor any agency thereof, nor Battelle Memorial Institute, nor any of their employees, makes any warranty, express or implied, or assumes any legal liability or responsibility for the accuracy, completeness, or usefulness of any information, apparatus, product, or process disclosed, or represents that its use would not infringe privately owned rights. Reference herein to any specific commercial product, process, or service by trade name, trademark, manufacturer, or otherwise does not necessarily constitute or imply its endorsement, recommendation, or favoring by the United States Government or any agency thereof, or Battelle Memorial Institute. The views and opinions of authors expressed herein do not necessarily state or reflect those of the United States Government or any agency thereof.

\author{
PACIFIC NORTHWEST NATIONAL LABORATORY \\ operated by \\ BATTELLE \\ for the \\ UNITED STATES DEPARTMENT OF ENERGY \\ under Contract DE-AC05-76RL01830
}

Printed in the Enited States of America

\author{
Available to $\mathrm{DOE}$ and $\mathrm{DOE}$ contractors from the \\ Office of Scientific and Technical Information, \\ P.O. Box 62, Oak Ridge, TN 37831-0062; \\ ph: (865) 576-8401 \\ fax: $(865) 576-5728$ \\ email: reports $a$ adonis.esti.gov
}

\begin{abstract}
Available to the public from the National Technical Information Service, U.S. Department of Commerce, 5285 Port Royal Rd., Springfield, VA 22161 ph: (800) 553-6847 fax: (703) 605-6900 email: orders $a$ ntis.fedworld.gov online ordering: http://www.ntis.gov/ordering.htm
\end{abstract}

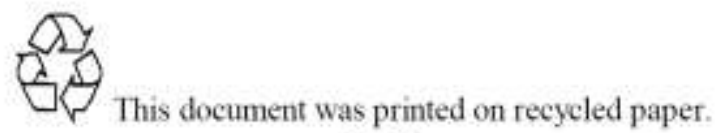




\section{Streamlining and Refining FEDS Loads Models - Final Report}

RT Dahowski

JA Dirks

December 2012

Prepared for

the U.S. Department of Energy

under Contract DE-AC05-76RL01830

Pacific Northwest National Laboratory

Richland, Washington 99352 



\section{Executive Summary}

The Facility Energy Decision System (FEDS) software is a powerful buildings energy analysis tool developed by Battelle at the Pacific Northwest National Laboratory with support from numerous organizations including several within the U.S. Department of Energy (DOE) and U.S. Department of Defense (DoD). FEDS has been used extensively within the federal sector to assess costeffective energy efficiency opportunities and provide recommendations for individual buildings and large building campuses and military installations for many years. Over that time the FEDS engine and code base have been updated and improved to support numerous functionality and feature enhancements. To meet current growing interest in building energy efficiency and add a variety of new features and capabilities increasingly sought by users to model today's building systems and technologies, a restructuring of the code base and update of the core load models was necessary.

The work described in this report was performed as part of a Cooperative Research and Development agreement (CRADA) between the U.S. Department of Energy's Pacific Northwest National Laboratory (PNNL) and Retroefficiency, Inc. Users of FEDS understand the value that it provides in analyzing opportunities in building energy efficiency to reduce energy use, electric demand, operating costs, and related environmental emissions for the hundreds of thousands of federal buildings across the nation. This report provides an overview of the various tasks performed under the CRADA. 


\section{Contents}

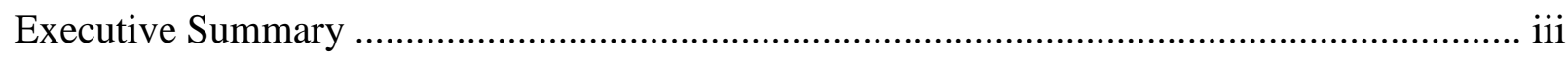



Summary of Progress on Streamlining and Refining FEDS Loads Models ........................... 2

Restructure and Update the FEDS Building Load Models ....................................... 2

Restructure and Update FEDS Central Plant and Thermal Loop Loads ............................. 2

Implement Equivalent Thermal Parameters (ETP) Model .............................................. 3

Add New Modeling Features ...................................................................................... 3

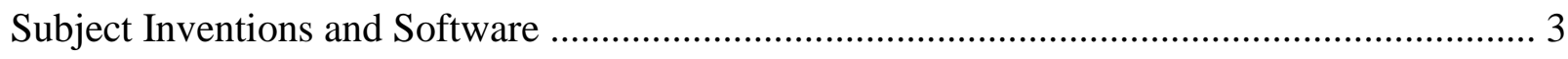

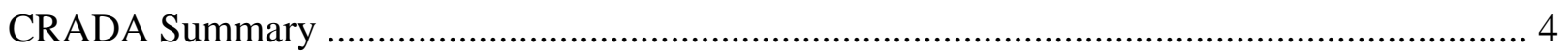





\section{Introduction}

The Facility Energy Decision System (FEDS) software is a powerful buildings energy analysis tool developed by Battelle at the Pacific Northwest National Laboratory. It is an easy-to-use tool that quickly and objectively identifies energy efficiency improvements that maximize life-cycle savings. The Windows-based program requires only minimal user experience and input to perform energy efficiency assessment screenings as well as detailed energy retrofit project analyses across a wide variety of building types, from single buildings to large multi-building campuses and installations. Unlike currently available building energy design tools, FEDS offers a number of unique features and benefits geared towards providing facility energy managers with the tools needed to quickly assess where energy is being used and which measures will help to reduce energy use and costs. The core functions of FEDS include:

- Requiring only minimal user input yet able to accept detailed building system parameters; FEDS estimates unspecified parameters based on characteristics typical for a building of the specified type, size, age, location, etc.

- Modeling cost and energy performance of heating, cooling, ventilation, lighting, motors, plug loads, refrigeration, building shell, and hot water systems, plus central plants and thermal loops.

- Calculating energy consumption and electrical demand for each technology, end use, building, and the entire installation, considering interactive effects amongst building systems and between buildings on a shared meter.

- Evaluating thousands of candidate energy efficiency options via a site optimized life-cycle cost minimization process.

- Reporting investment requirements, net present value, and payback period, plus pre- and post-retrofit energy consumption and costs, and air pollutant emissions impacts.

FEDS is highly flexible and can help to quickly perform a range of energy management and forecasting functions, such as evaluating fuel switching opportunities, new technologies, and the impacts of change - including changes to energy rates, occupancy or mission, and more. The combination of power, versatility, and ease of use that FEDS provides enables facility energy managers, operators, and owners the ability to set energy goals and identify a path towards reaching them.

FEDS has been used extensively within the federal sector to assess cost effective energy efficiency opportunities and provide recommendations for individual buildings and large building campuses and military installations for many years. Over that time the FEDS engine and code base have been updated and improved to support an increasing level of functionality and feature enhancements. To meet current growing interest in building energy efficiency and add a variety of new features and capabilities increasingly sought by users to model today's building systems and technologies, a restructuring of the code base and update of the core load models was necessary.

The work, as performed under this CRADA, represents a component of a larger effort to reshape the FEDS software, to update its foundation and expand its features and usability to meet the strong and growing demands for examining energy efficiency options as well as energy security and emissions 
reductions and their associated costs. The overall effort is designed to help FEDS fully realize its potential in the existing and emerging energy, resource, and grid integration analysis arenas. The work completed under this CRADA project will help to enable the types of additional functionality and capabilities sought by FEDS users. The focus of the work under the CRADA was on the restructuring and updating of pieces of the FEDS energy analysis codebase, from reorganizing and streamlining the core loads and consumption profiles, to updating the mass storage approach in order to facilitate the implementation of a host of new features and capabilities to improve the accuracy and flexibility of FEDS building simulations.

\section{Summary of Progress on Streamlining and Refining FEDS Loads Models}

There were four main focus areas under the CRADA project:

1. Restructure and Update the FEDS Building Load Models,

2. Restructure and Update FEDS Central Plant and Thermal Loop Loads,

3. Implement Equivalent Thermal Parameters (ETP) Model, and

4. Add New Modeling Features.

\section{Restructure and Update the FEDS Building Load Models}

This task focused on updating the FEDS core loads models to provide a more flexible, consistent, thorough, and useful set of load and consumption profiles. The goal of this effort was to enable the addition of important new functionality for such things as modeling enhanced occupant specificity, building system controls, generation, and energy security evaluations.

The work under this task focused on restructuring the loads models applied to such areas as occupants, lighting, service hot water, motors, and miscellaneous plug loads. Separate hourly profiles for building operation and occupancy have been constructed and stored and consistent load profiles developed and tracked for each of the building technology end uses. This has enabled more seamless modeling of additional schedule types plus schedule anomalies such as leap year and daylight saving time. The result provides a more consistent approach offering greater modeling flexibility and reducing the number of different times that the loads must be generated. Changes have been implemented within the core loads models themselves and output reports to reflect some of these changes.

\section{Restructure and Update FEDS Central Plant and Thermal Loop Loads}

The FEDS software is unique in its ability to integrate campus-wide building energy efficiency analysis with an examination of central heating and cooling plants and their thermal distribution loops. Under this CRADA project, PNNL anticipated enhancing the tracking of central plant and thermal loop loads and central fuel consumption throughout the system from the point of generation, through distribution and associated losses, to the ultimate end uses at the individual building and technology level Logic improvements were also planned that would better enable 
FEDS to track changes in energy and demand valuations as buildings and other energy systems are optimized throughout the building and central plant optimization process.

Due to changes in project cost burdening, the contemplated improvements planned within this task were not completed. While early planning and design evaluations were commenced, no coding or substantive changes to the central plant and thermal loops module were performed prior to the conclusion of the project.

\section{Implement Equivalent Thermal Parameters (ETP) Model}

This task was designed to more completely implement the ETP method throughout FEDS to update the internal gains handling of the HVAC loads model. The ETP model is a reduced form model that effectively collapses the complexity of much more detailed thermal models to the equivalent thermal parameters in which parallel heat flow paths and series thermal mass elements are lumped into fewer parameters.

Combined with the restructured loads models, the updates to the handling of heat gains will further support the advanced and more flexible building system simulation that FEDS users are seeking. The changes will improve FEDS ability to handle multiple variations of schedule types and system control options. The changes further improve the allocation of gains that go to the mass compared to the portion that goes into the air in any modeled time step, improving both the accuracy and the flexibility of the HVAC loads model, enabling much greater variation in modeling capability going forward.

The team completed a significant portion of the work for this task under the CRADA project. A detailed design specification was developed, describing the coding changes necessary to complete the transition. Additionally, appropriate coefficients for the ETP model parameters were derived and evaluated in the context of building system heat transfer between air and building mass systems under varying states and conditions. With the completion of the loads restructuring and update to hourly profile handling within task 1 , the implementation of this updated approach is nearing fruition.

\section{Add New Modeling Features}

In order to achieve some tangible early benefit from this restructuring work and updates within the other tasks, this task focused on implementing new modeling features to FEDS that utilize the new capabilities. With remaining resources, the research team prioritized and implemented some key new functionality and modeling options. These included updates for more flexible zone level calculations, HVAC model improvements, additional HVAC technologies, and more.

\section{Subject Inventions and Software}

There are no subject inventions to report from either party to the CRADA. 


\section{CRADA Summary}

The Pacific Northwest National Laboratory (PNNL) has been developing and expanding the Facility Energy Decision System (FEDS) energy analysis tool over many years, with support from numerous organizations including several within the U.S. Department of Energy (DOE) and U.S. Department of Defense (DoD). FEDS is used extensively throughout the federal sector to examine building energy efficiency potential and recommend energy saving retrofit projects. The focus of this CRADA was to update the foundation of the FEDS loads models, to improve the core functionality and calculation methods and position the building efficiency analysis software for continued growth. The broader intent was to increase FEDS utility and user satisfaction via improving modeling accuracy, facilitating development and making possible a wide range of new and desired capability enhancements. Due to changes outside of the project team's control, not all of the goals of the CRADA project were able to be achieved; however, significant progress was made in several areas which better position FEDS to meet the challenges of the growing national interest in building energy efficiency. 



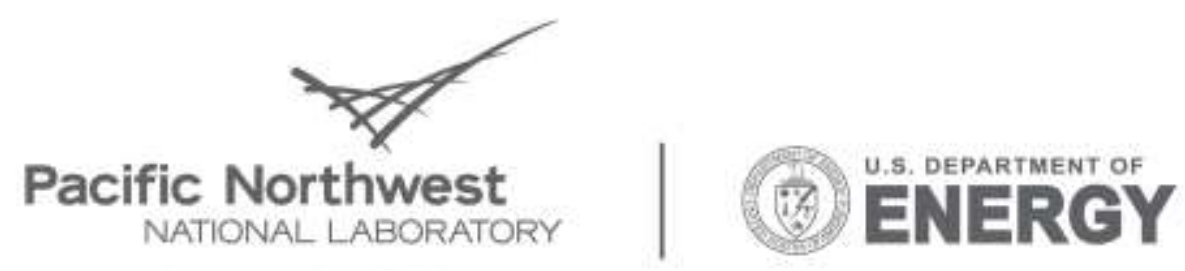

Proudly Operated by Ballelle Since 1965

902 Battelle Boulevard

P.O. Box 999

Richland, WA 99352

1-888-375-PNNL (7665)

www.pnl.gov 